\title{
ESTRATÉGIA E JAZZ: UM NOVO PROCESSO DE FORMULAÇÃO ESTRATÉGICA
}

\author{
Juliano Lissoni ${ }^{1}$ \\ Alexandre Marino Costa 2 \\ Gilberto de Oliveira Moritz ${ }^{3}$ \\ Maurício Fernandes Pereira 4
}

Resumo: A definição do que é estratégia e de como é formulada tem sido pauta de constante discussão. Este artigo propõe uma condensação do tema, de forma a considerá-la como uma combinação de momentos, que parte da intenção e do plano e permite a derivação a partir da improvisação. A conclusão a que se chega é que a formulação da estratégia se assemelha ao jazz, na execução do qual a experimentação e a improvisação se juntam à partitura de forma a proporcionar à audiência momentos mágicos. Foram a improvisação e a experimentação que escreveram a evolução do jazz, pois incursões bem sucedidas originaram derivações significativas que transformaram o ritmo em música moderna sem que sua identidade fosse descaracterizada. Assim ocorre nas empresas, onde tentativas e improvisações podem levar à evolução da estratégia empresarial.

Palavras-Chave: Formulação Estratégica. Estratégias Derivadas. Jazz.

\section{INTRODUÇÃO}

O que é estratégia? Como é formulada? Por muito tempo estas perguntas têm ocupado a mente dos pesquisadores e especialistas na área. Mintzberg (1986) definiu-a como uma ferramenta gerencial fundamental para as organizações e desde a abordagem clássica de Chandler (1962) e Ansoff (1965) o tema já foi o foco de acaloradas discussões por todo o planeta. As respostas dadas a essas perguntas têm sido no sentido de classificar e dividir a estratégia em escolas de pensamento não a considerando como um processo em desenvolvimento que agrupa diferentes momentos: da deliberação à tentativa, da tentativa à improvisação, e da improvisação à derivação. O resultado acaba sendo uma combinação entre deliberação e aprendizado.

O objetivo deste ensaio é fazer uma revisão sobre o conceito de estratégia de acordo com as escolas de pensamento já apresentadas pelos principais autores da área. Compara-se o conceito à evolução do jazz, estilo musical no qual o músico busca, a partir de uma partitura construída, esquecer das regras e dos dogmas e se entregar às nuances do seu ritmo, gerando um combinado que mistura uma linha musical estabelecida com a liberdade e a inquietação, gerando frases musicais ao mesmo tempo desorientadas e magistrais. $E$ foi este jazz, que permitiu que a criatividade aplicada à partitura, 0 pensamento à ação, que evoluiu e se tornou moderno sem perder suas características.

No campo do tema o resultado desse processo que se convencionou chamar de estratégia deliberada, impulsionada pelos movimentos de "tentativa-e-erro" ou improvisação, é complementada com variações sobre o plano estipulado, entendidas como derivações, ou denominadas neste ensaio

\footnotetext{
1 UNISUL, Florianópolis, SC. E-mail. julianolissoni@gmail.com

2 Departamento de Ciências da Administração, UFSC, Florianópolis, SC. E-mail: marino@cse.ufsc.br

3 Departamento de Ciências da Administração, UFSC, Florianópolis, SC. E-mail: gomoritz@cse.ufsc.br

4 Departamento de Ciências da Administração, UFSC, Florianópolis, SC. E-mail: mpereira@cse.ufsc.br
} 
de estratégias derivadas. Assim, pode-se entendê-las não como meios para se chegar a um fim, mas como processos que não param complementados ou modificados a cada passo, nos quais o fim previamente estabelecido pode ser alcançado ao mesmo tempo em que outros fins podem surgir.

\section{ASPECTOS TEÓRICOS DA FORMULAÇÃO DA ESTRATÉGIA}

A concepção de estratégia empresarial apresenta-se como uma disciplina a partir dos anos sessenta com a abordagem clássica de Alfred Chandler (1962), Alfred Sloan (1963) e Igor Ansoff (1965) cujo enfoque baseava-se no distanciamento entre concepção e execução, numa deliberação de metas e uma seqüência lógica de ações. De acordo com Chandler (1962, p.13) "estratégia é a determinação de metas e objetivos básicos e de longo prazo de uma empresa; e a adoção de ações e alocação de recursos necessários para atingir esses objetivos".

Whittington (2002) apresenta quatro perspectivas genéricas sobre estratégia: a abordagem clássica, mais antiga e influente, que é baseada no processo racional e deliberado e acredita no planejamento para adaptação ou antecipação às mudanças de mercado; a abordagem evolucionária, apoiada na metáfora da evolução biológica ancorada na imprevisibilidade do ambiente e que aconselha os estrategistas a manter custos baixos e opções aberta, na expectativa de que os mercados garantam a maximização do lucro; a abordagem processualista, baseada no aprendizado organizacional no qual as estratégias emergem do envolvimento íntimo com as operações e forças da organização; e a abordagem sistêmica, que reflete os sistemas sociais dos quais ela participa, sendo que o caminho da estratégia é jogar pelas regras locais.

Para Whittington (2004, p.21), "o desafio para a estratégia é que muitos teóricos evolucionistas duvidam da capacidade das organizações em alcançar a diferenciação e adaptar-se de um modo deliberado e sustentável". Esta linha evolucionista encontra várias críticas, como as apresentadas por De Geus (1998) considerando que, apesar da crença darwinista de que a evolução se deu através da ecologia das espécies, a pesquisa do zoólogo/bioquímico Allan Wilson, da Universidade da Califórnia, em Berkeley, mostra que o comportamento de determinada espécie, e não as mudanças ambientais, era a principal força propulsora da evolução. Algumas espécies conseguiam evoluir mais rapidamente porque exibiam um tipo especial de comportamento, dotado de três características especificas: inovação, propagação social e mobilidade.

No entanto, a abordagem da adaptação gradual teria uma racionalidade própria, que foi denominada por Quinn (1980) apud Whittington (2004), de incrementalismo lógico, cuja racionalidade superior estaria na consciência da existência da própria racionalidade limitada. Para Mintzberg (1987) apud Whittington (2004, p.28), "os estrategistas astutos entendem e aceitam que não podem ser astutos o suficiente para pensar sobre todas as coisas antecipadamente", considerando que 0 incrementalista lógico está comprometido com a experimentação e com 0 aprendizado. 0 autor sustenta que esta abordagem não seria necessariamente tática, e poderia ser considerada a partir de uma "lógica subjacente" ou "intento estratégico" com clareza necessária para prover a direção e com amplitude a ponto de permitir a flexibilidade e o oportunismo.

O conceito de "intenção estratégica" ganhou força com Hammel e Prahalad (1989). Os autores sustentaram que as empresas que se tornaram bem sucedidas o fizeram porque mantiveram uma obsessão pela liderança global. Essa obsessão foi denominada intenção estratégica, cuja base estava no estabelecimento de uma meta que merece esforço pessoal e comprometimento, muito embora com um relacionamento diferente entre meios e fins. Para Hamel e Prahalad (1989, p.54), "conquanto a intenção estratégica seja clara no que se refere aos fins, ela é flexível quanto aos meios - e deixa campo para improvisações. Conseguir a intenção estratégica exige enorme criatividade com relação aos meios". Isto ocorre, pois ela é estável ao longo do tempo e deve proporcionar consistência às 
ações de curto prazo, da mesma forma em que deixa espaço para reinterpretações à medida que novas oportunidades emergem. Está focada em atingir a liderança batendo os competidores. A intenção estratégica pode ser entendida a partir do conceito de visão, ou seja, uma noção de destino ou um alvo. Para Hamel e Prahalad (1995, p. 154), "a intenção estratégica deve ser o objetivo que comanda o respeito e o compromisso de cada funcionário".

A Petrobrás exemplifica esse conceito ao investir para se tornar dona ou sócia de algumas das maiores empresas do setor de gás, além do investimento em termelétricas e redes de distribuição, sinaliza de forma clara que busca tornar-se uma potência em todo o setor de energia. A empresa comprou de forma simultânea a operação no Brasil da italiana Agip, a distribuidora de GLP e a mineira da Casmig. A Petrobrás deverá aplicar até 2010, aproximadamente 9 bilhões de dólares na ampliação da capacidade de produção, transporte e distribuição de gás. Estes movimentos denotam que a empresa busca ser menos uma companhia de petróleo e mais uma empresa integrada de energia. De acordo com Dieguez (2004, p.62), "o ímpeto com que a Petrobrás vem investindo nesse mercado deixa pouca margem de dúvida sobre sua disposição de assumir a liderança incontestável do setor".

A intenção estratégica pode ser relacionada com a abordagem de negócio apresentada por Levitt (1960) que pregava que a empresa precisaria definir exatamente qual o seu negócio, definir seus pontos fortes e fracos e estabelecer uma cadeia de valor necessária para sua atuação. Essa pelo menos parece ser a lógica por trás das ações da Petrobrás ao posicionar-se como empresa de energia. De acordo com Levitt (1960), um dos enganos mais comuns nas organizações é supor que o simples crescimento no mercado seja o fator decisivo, baseado na superioridade inquestionável de seu produto. Esta armadilha é bastante comum quando a empresa está preocupada com os meios e não com os fins, ou seja, quando está orientada para o produto e não para o cliente. Levitt (1960) sustentou esta afirmação exemplificando-a com caos de setores inteiros, tais como as ferrovias, que, segundo Levitt (2004, p. 88) "permitiram que outras tomassem seus clientes porque supunham que seu negócio era 0 ferroviário, e não o de transportes".

Este ciclo, batizado por Levitt (2004, p. 91) de "ciclo de auto-engano de expansão abundante e decadência despercebida" é fundamentado em quatro condições: a primeira supõe que há um crescimento populacional capaz de absorver o que for criado e produzido, fazendo com que a empresa tenha uma tranqüilidade excessiva em relação ao mercado; a segunda condição coloca o produto como absoluto, inquestionável e indispensável, sem substituto competitivo; a terceira supõe que a combinação entre volume e queda de custos é capaz de garantir o consumo em massa; e finalmente, a redução dos custos de manufatura através da melhoria de processos utilizando a experimentação científica.

Para Levitt (2004, p.98) "é vital que toda pessoa envolvida em negócios entenda a visão de que um setor é um processo de satisfação do cliente, não de produção de mercadorias". O movimento deve ser no sentido de entender o que poderá satisfazer a necessidade dos consumidores, para então partir para a criação e desenvolvimento do produto e encontrar as melhores matérias-primas para fazê-lo. $E$ é este, de acordo com Tellis et al (2002) um dos componentes distintivos da visão. Para Allen (1998, p.18) "para ser realmente eficaz, a visão deve ser bastante coerente para criar uma imagem identificável do futuro, ser bastante convincente para gerar comprometimento com o desempenho, enfatizar o que pode ser e esclarecer o que deve ser".

No entanto, Chakravarthy (1997) considera que em indústrias sujeitas a turbulências significativas a intenção estratégica não funciona mais e, nestes casos seria impossível estabelecer uma intenção de longo prazo, pois ela seria sempre temporária. Para o autor a guerra da estratégia está fundamentada no conceito de substituição, e não mais no de imitação; atualmente há um grande leque de substituições possíveis vindas de vários lados, que considera que mesmo que a empresa seja muito boa no que faz os concorrentes mais inteligentes não seguiriam o paradigma anterior da imitação e sim desenvolveriam uma nova estratégia de substituição. Para Chakravarthy (1997), "hoje, o desafio da estratégia é este, se tomarmos o exemplo de um ator: no dia de hoje ele faz comédia, amanhã 
representa uma tragédia, depois interpreta um musical, enfim, vai fazendo várias coisas. Continua ator, mas pode mudar de papéis (...). No entanto, há constância, existem âncoras".

Ao analisar-se a história da Sony, observou-se que a empresa lançou um dos produtos de maior sucesso no mundo da eletrônica de consumo, o walkman, e fez dessa marca uma palavra utilizada em vários idiomas, tão usada quanto Xerox, Maizena ou Gilette. No entanto, agora o sinônimo de música que cabe no bolso é outro: 0 iPod da Apple que carrega músicas da Internet. A Sony largou atrasada nessa corrida do entretenimento digital. O próprio executivo-chefe da Sony, Nobuyuki Idei, compara a indústria dos eletroeletrônicos a dinossauros atingidos por uma chuva de meteoros.

A Sony tem pela frente os desafios da internet, pois em menos de cinco anos, o fenômeno MP3 transformou a rede de computadores em veículo de consumo de música sendo que o mesmo está prestes a acontecer com o cinema e a televisão; a atual disputa é pelo controle da sala de estar dos consumidores. São poucos os que duvidam de que tudo o que hoje é consumido na forma de CDs, DVDs e sinais de TV cedo ou tarde vá se transformar em bits que entrarão nas residências por meio de uma conexão com a internet. Outro aspecto a destacar é que durante muito tempo a Sony manteve sob seu domínio o terreno de televisores, no entanto, presa a glórias passadas demorou a investir na tecnologia de cristal líquido que permite imagens mais nítidas e telam mais finas e elegantes.

$O$ exemplo sugere que a Sony não foi imitada. Foi substituída. Segundo levantamento da $E$ Consulting (Revista Exame de 27/01/05), nos anos 70 uma inovação na área de telecomunicações levava aproximadamente três anos para ser imitada e atualmente leva apenas nove meses. A Sony que fora pioneira em dispositivos musicais portáteis, agora é seguidora da Apple de Steve Jobs. A empresa, cuja liderança era inegável, deixou de "improvisar" e perdeu terreno. O caso da Sony sugere uma comprovação da citação de Hamel e Prahalad (1989, p.55) de que "poucas vantagens competitivas são duradouras".

Para Porter (1996, p. 64), "estratégia competitiva é sobre ser diferente. Isto significa escolher deliberadamente um conjunto diferente de atividades de forma a entregar um mix único de valor". Essa abordagem está calcada no contexto posicionamento produto-mercado. O modelo de hipercompetição proposto por D'Aveni (1994) é entendido por Porter (1999) como uma autoflagelação, ocasionada pelo ritmo frenético da mudança no conjunto de regras, fazendo com que a flexibilidade se imponha sobre 0 posicionamento. Segundo Porter (1999, p. 47) "a raiz do problema é a incapacidade de distinguir entre eficácia operacional e estratégia". A diferença sustentável faz com que a empresa supere seus concorrentes. A eficácia operacional está relacionada com superar os concorrentes "fazendo melhor". O posicionamento estratégico, por sua vez, está relacionado com a diferenciação, seja através de atividades diferentes ou 'fazer diferente' as mesmas atividades.

A principal vantagem do posicionamento estratégico é sua capacidade de fazer com que a empresa tenha êxito no longo prazo, já que a disseminação de melhores práticas e a forma com que elas são absorvidas é característica fundamental da eficácia operacional, e é de fácil proliferação. Outra razão que comprova a insuficiência da eficácia operacional é a convergência competitiva, que faz com que a competição se torne uma corrida cuja trajetória é a mesma para os concorrentes. 0 êxito no longo prazo referido está diretamente relacionado com encontrar uma posição no setor em que a empresa possa influenciar as forças competitivas em seu favor. Tendo a matriz das forças competitivas como base, observa-se que a empresa está sempre sendo alvo, seja pela ameaça de entrada de novos concorrentes, fornecedores ou compradores poderosos que possam promover integração vertical de suas atividades para frente ou para trás, produtos substitutos, além é claro, da intensa rivalidade entre os concorrentes estabelecidos na indústria.

Segundo Porter (1999), as posições estratégicas são oriundas de três fontes: o posicionamento baseado na variedade, o posicionamento baseado nas necessidades e o posicionamento baseado no acesso. Além disso, é sempre conseqüência da diferenciação na oferta de atividades. No entanto, mesmo com a escolha de uma posição exclusiva, a empresa ainda poderá ser alvo dos concorrentes que se reposicionam para alcançar um desempenho superior. Esta abordagem também sustentada por 
Chacravarthy (1997) ao tratar da relação entre imitação e substituição. A estratégia também pode ser entendida pela combinação de atividades, através da criação de uma cadeia de valor exclusiva. Este é contexto da compatibilidade, que pode ser definida a partir de três tipos: simples consistências, reforço mútuo das atividades e otimização do esforço. De acordo com Porter (1999, p. 71), "a vantagem competitiva emana da totalidade do sistema de atividades". Finalmente, a estratégia diz respeito a escolher o que não fazer. Ou seja, a consciência clara do verdadeiro negócio da empresa evita desgastes provenientes da ampliação do foco.

A visão de Porter sobre a formulação da estratégia está ancorada no posicionamento da empresa, na influência no equilíbrio de forças por meio de ações e na antecipação de mudanças nos fatores básicos das forças, escolhendo uma maneira apropriada ao explorar a mudança. A influência no equilíbrio das forças, especificamente, está relacionada com a capacidade da ação em alterar as causas destas forças. Na visão de Porter (1999), estratégia diz respeito, acima de tudo, em pensar não somente como é agora o negócio, o mercado, os concorrentes e o ambiente em geral, e sim, como o serão no futuro. Hamel e Prahalad (1995) reforçaram este aspecto ao considerar a importância da empresa criar os "mercados de amanhã".

Para Markides (2000), estratégia é algo que permite à empresa estabelecer uma posição em seu mercado e esta posição não necessariamente deve mudar com freqüência. Se surge a necessidade de inovação, a nova posição irá emergir das idéias e ações das pessoas na organização. Markides vê a estratégia como a busca por uma posição única na indústria. Para o autor (2000), essa se origina das respostas que a empresa deve dar a três questões: quais consumidores escolher, o que oferecer a estes consumidores, e como fazer isto de forma mais eficiente. Empresas que falham ao fazer escolhas claras nestas dimensões navegam sem uma direção clara até o momento em que quebram. Markides (2000) defende que 0 aprendizado estratégico pode se originar tanto do planejamento formal quanto do modelo de tentativa-e-erro. Wall (2004) defende um modelo de estratégia baseado na improvisação, para a qual a organização necessita de um foco coerente associado ao planejamento tradicional ao mesmo tempo em que desenvolve a flexibilidade para responder às mudanças de mercado, sendo que a implementação - ou ato de improvisar - leva ao desenvolvimento ou modificação da estratégia.

Na visão de Mintzberg (1967, p.72), "estratégia é definida simplesmente como o processo de tomar decisões organizacionais importantes". Nesta proposição, o autor sugere um modelo para a formulação da estratégia: inteligência - desenho - escolha: coletar e analisar informações, desenhar alternativas e avaliar as conseqüências e para finalizar escolher uma alternativa. Esta visão é baseada na característica primordial defendida por Minztberg (1967, p.73): "a estratégia evolui. Uma organização muda com o passar do tempo à medida que os administradores tomam novas e importantes decisões". Considera que esses conceitos apresentam-se como partes de um todo maior que seria maior do que a soma das mesmas. Nesta proposição, o autor divide os conceitos de estratégia em nove escolas e apresenta uma décima que seria uma visão ampla do conceito agrupando todos os anteriormente existentes. Além disso, Mintzberg afirma também que as escolas da estratégia são divididas em grupos de natureza prescritiva, descritivas ou ambas.

$\mathrm{Na}$ proposta de Mintzberg, as escolas são divididas da seguinte forma: Concepção - a estratégia é perspectiva, planejada e única; Planejamento - a estratégia consiste na divisão em micro estratégias e programas; Posicionamento - baseia-se em posições genéricas planejadas e estratagemas; Empreendedorismo - a estratégia está baseada na figura do empreendedor, como uma perspectiva e visão única; Cognição - baseia-se na perspectiva intelectual; Aprendizado - é a estratégia por esquemas e única; Poder - defende a estratégia obtida através de posições e esquemas políticos e cooperativos; Cultura - defende a estratégia como perspectiva coletiva única; Ambiente baseada nos teóricos da contingência, vê a estratégia como posições específicas; Configuração defende a estratégia como variante dependendo do contexto organizacional. 
Mintzberg (1985) caracterizou os tipos de estratégia nomeando-as: Planejada manifesta-se através de intenções claras e articuladas, reforçadas por controles formais de forma a assegurar sua busca, num ambiente que é aquiescente. Empreendedora cuja visão, provê somente um sentido geral de direção, os detalhes podem emergir durante a rota e o detentor da visão pode reformulá-la, além de considerar que visões provenientes de um único cérebro são mais flexíveis. Ideológica baseia-se no fato que muitas vezes os padrões são obtidos por meio da visão coletiva sendo mais dificultoso mudála do que àquela cuja visão é individual. "Guarda-chuva" trata-se de linhas gerais de comportamento sob as quais as ações da organização devem se encaixar e os que possuem a visão não controlam sua realização. Processo a liderança controla o processo da estratégia enquanto que o conteúdo da mesma fica com os demais atores. Desconectada é observada quando uma unidade e negócio ou subunidade estabelece um padrão diferente de ações e este tipo está relacionado ao que Nadler e Tushman (1995) denominaram de organizações ambidestras. Consenso cujos diferentes atores naturalmente convergem no mesmo tema ou padrão, de forma que isto se torna difundido na organização, sem a necessidade de direção ou controle central, deriva mais da ação coletiva do que da intenção coletiva. Imposta é aquela a cujos padrões de ação são forçados pelo ambiente, apesar da presença de controle. Para Mintzberg (1985, p.270), "o entendimento de como estes diferentes tipos de estratégia combinam-se e tendem a se auto-sequenciar ao longo do tempo em diferentes contextos poderia revelar um bom argumento para o processo de formulação da estratégia".

Outra significativa contribuição de Mintzberg para o estudo da estratégia está na definição da mesma a partir dos conceitos de plano, pretexto, padrão, posição e perspectiva. Dentro deste alinhamento, o autor defende que pensamento e ação ocorrem na mesma esfera, sendo, portanto, indissociáveis. Estabelece a relação entre estratégia como plano que pode ser desdobrada em estratégia efetivada ou não. Dentro da mesma linha, demonstra a relação com as estratégias emergentes, que a partir de sua efetivação também são estratégias realizadas.

Para Mintzberg (1985, p.257), "comparando-se a estratégia intencionada com a estratégia realizada tem nos permitido distinguir estratégias deliberadas - que são realizadas como intencionadas -, de estratégias emergentes - padrões ou consistências percebidas apesar ou na ausência de intenções". Para a estratégia ser considerada deliberada três condições devem ser satisfeitas: intenções precisas na organização, comum virtualmente a todos os atores e realizada exatamente como intencionada. Já para uma estratégia ser considerada emergente deve haver ordem e consistência de ação ao longo do tempo. Para Mintzberg (1985, p.270), "a diferença fundamental entre estratégias deliberadas e emergentes é que enquanto a primeira está focada na direção e controle executando o que foi desejado - a segunda abre a possibilidade do aprendizado estratégico". É importante, contudo observar que, nessa linha, estratégias emergentes não significam o caos total, mas sim ordem não intencional.

Mintzberg (1985) defende que a estratégia deliberada, o plano, pode encontrar um ambiente com uma rotação de mudança acelerada e, portanto, ter de sofrer modificações oriundas de respostas ao mercado. E que isto é parte da estratégia. Segundo Mintzberg (1967, p.71) "existem aqueles que conseguem ver grandes formas calculadas para a entidade corporativa, e existem os que citam a prática corrente para argumentar que a estratégia organizacional evolui desenhada menos pelo homem e mais pelo seu ambiente". E complementa (1967, p.74): "decisões estratégicas não são calendarizadas. Elas são tomadas quando problemas e oportunidades aparecem".

Assim, Mintzberg (1998, p. 424) sustenta que "estratégias podem se formar assim como ser formuladas. Uma estratégia realizada pode emergir como resposta a uma situação em evolução ou pode ser introduzida deliberadamente, através de um processo de formulação seguido de implementação". Ao considerar esta proposição, sugere que não se pode separar pensamento e ação. Mintzberg (1998, p. 420) considera que o estrategista deve "conhecer as capacidades da organização 0 suficiente para pensar profundamente sobre a direção estratégica". E sustenta: "planejamento estratégico não pode ser sinônimo de formulação da estratégia" (Mintzberg, 1985, p.29). Talvez aqui 
resida a grande crítica ao modelo de Porter e Ansoff, cujos traços clássicos de estratégia separavam pensamento de ação. Para Anderson (1994, p.107), "Michael Porter em citação na The Economist, resumiu a situação: 'as críticas ao planejamento estratégico são merecidas. O planejamento estratégico em muitas empresas não tem contribuído para o pensamento estratégico"'. E complementa (1994, p.108): "algumas vezes não conseguimos saber nem mesmo sobre o futuro imediato, e, como 0 horizonte de tempo se expande em nossa frente, o que pensamos que iria ocorrer em um ano ou dois, ou cinco no máximo, muda de uma tentativa de adivinhação para pura esperança". Em sua resposta a Igor Ansoff, Mintzberg (1991, p.465) cita: "é óbvio que precisamos pensar. É óbvio que queremos ser racionais. Mas existe um mundo complicado lá fora. Sabemos que iremos a lugar nenhum sem 0 aprendizado emergente ao lado do planejamento deliberado".

\section{ESTRATÉGIAS EMERGENTES OU DERIVADAS?}

Em "A Criação Artesanal da Estratégia", Mintzberg (1998) assume que o comparativo que originou a teoria das estratégias emergentes surge a partir da estratégia como perspectiva, que é influenciada pela cultura organizacional ou pelo caráter. Jack Welch (2003) chamou a de "identidade". Outros autores denominam-na como "personalidade" da empresa. Para Minztberg um dos grandes desafios do estrategista está em conhecer as capacidades da organização de forma suficientemente sustentável a ponto de definir sua direção estratégica. Ao comparar o trabalho do estrategista com 0 de uma escultora, o autor propõe ambos estão situados entre suas experiências passadas e suas perspectivas para o futuro.

Na comparação, ao abordar o desenrolar do trabalho de uma escultora, que de uma idéia que tinha para uma obra, no desenrolar da ação chegou a concretizá-la, Mintzberg (1998, p. 420), cita que "ela (a escultora) sabe exatamente o que funcionou e o que não funcionou no passado". Acrescenta que os estrategistas, "como a escultora, situam-se entre um passado de capacidades empresariais e um futuro de oportunidades de mercado".

Ao tratar a questão de quem é o estrategista da organização, o autor chama a atenção para 0 fato de que as estratégias propostas não são implementadas devido a visão antiga que se tem dessas. No entanto, entende-se que o problema não está em considerar esta ou aquela visão e sim, de considerar qual é o fluxo de informações dentro da organização e ainda, se esta é voltada para 0 pensamento estratégico. Pouco adianta a empresa considerar a estratégia como padrão se não possui a cultura (ou perspectiva) de pensamento dentro da organização como um todo. Ou seja, a própria proposição de Mintzberg encontraria problemas em organizações que vêem a estratégia como um processo top-down, ou seja, de cima para baixo.

Ao descrever o processo de formulação da estratégia, Mintzberg (1998, p. 423) sustenta que nas organizações o desenvolvimento acompanha o trabalho da escultora, que de um objeto chegou a outro e conclui que "a ação estimulou o pensamento e isso acarretou o surgimento de uma estratégia". No entanto, segundo Levitt (1960), observa-se que o ponto crucial de qualquer empresa é definir qual é seu negócio. Então, utilizando o exemplo da própria escultora, ela definiu primeiro o que seria, ou seja, ser escultora. Assim, se ao tentar fazer um biscuit, produziu um vaso cilíndrico, é uma derivação da intenção estratégica de produzir a peça e do desdobramento da sua definição de negócio que é ser escultora. Então, pode-se sugerir que a seqüência de peças criadas é derivada da intenção estratégia original.

Tomando o caso da NFB (National Film Board of Canada) citado por Minztberg (1988): a empresa por uma circunstância de mercado acabou desenvolvendo um padrão para viabilizar a produção de seus filmes. No entanto, o negócio que deu origem às suas estratégias deliberadas e às "emergentes" permaneceu inalterado. Buscou-se apenas um meio adicional para realizar seu fim 
proposto, corroborando o conceito de Hamel e Prahalad (1989) de que a intenção estratégica seja clara no que se refere aos fins é flexível quanto aos meios. A NFB adotou um canal diferenciado que facilitasse seu projeto original. Outro caso ocorrido foi o da produção de séries para TV. Entrar nesta indústria em ascensão na década de 50 aconteceu sem que a concepção original de negócio fosse alterada. A NFB a partir de uma definição de negócio e de uma arquitetura estratégica, usando seus recursos de equipamento e capital intelectual, encontrou outro canal que não simplesmente emergiu, e sim, derivou da proposição original. Assim, o que Mintzberg (1998) denominou estratégia emergente, na verdade é uma estratégia derivada da intenção estratégica. Ao se relacionar com as teorias de Porter, Hamel e Prahalad, observa-se que a empresa está na verdade adotando uma variação sobre seus meios a partir de uma intenção. Portanto, as estratégias não surgiram simplesmente, e sim, derivaram o que colocou a própria estratégia em outro patamar.

O próprio Minztberg (1998, p.424) apresenta o modelo como derivado ao invés de emergente ao considerar que "uma estratégia realizada pode emergir como resposta a uma situação em evolução". Desta forma, o autor admite que a situação em evolução necessitou de uma resposta diferenciada. Mas, de qualquer forma, não se trata de uma situação totalmente nova, e sim em evolução, seja ela incremental ou descontínua. A mudança descontínua parte da reinvenção do negócio. No entanto, a inovação não surge do nada, ela é o resultado da relação entre planejamento e circunstâncias e não do fato de se fazer várias apostas. A situação em evolução não necessitou de uma nova estratégia, e sim, de um modelo que poderia ser derivado do plano original. Ao buscar sua intenção estratégica e organização estabelece um curso de ação, uma reta. Ao modificar sua linha par adaptar-se a esta "situação em evolução" a empresa se move dentro da variância da reta, ou seja, através de proposições derivadas. Assim, um novo modelo para a proposição estratégica poderia ser:

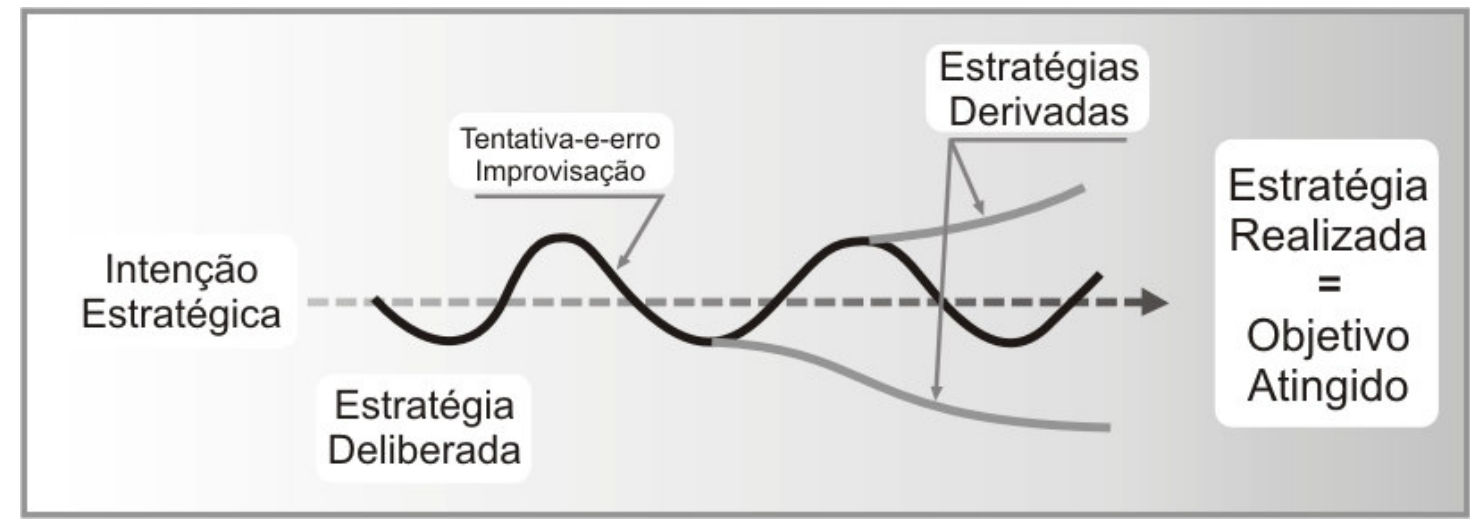

\section{Figura 1 - Um novo modelo de formulação estratégica}

Fonte: desenvolvido pelos autores

A intenção estratégica representa 0 início do caminho. A estratégia representa a ponte entre 0 que a empresa faz hoje e suas aspirações para o futuro. Se deste processo surgir um desdobramento para um novo negócio, esse fará parte da curva de expansão, derivada da intenção estratégica que consiste em uma deliberação que se desdobra por dois caminhos: o alcance do plano previamente proposto respeitando-se as variações provocadas pelas mudanças no mercado, ou a derivação para uma nova alternativa que poderá gerar a expansão para um novo modelo de negócio, mas cujo foco ou posicionamento da empresa poderá ser mantido.

Ao passo que a intenção estratégica representa o início do caminho, a estratégia representa a ponte entre 0 que a empresa faz hoje e suas aspirações para o futuro. Se desse processo surgir um novo negócio, este fará parte de uma curva de expansão - derivada de uma intenção estratégica - que 
se desdobra por dois caminhos: 0 alcance do plano previamente proposto, respeitando-se as variações provocadas pelo mercado, ou a opção por uma alternativa capaz de gerar um novo modelo de negócio, no qual o foco ou posicionamento da empresa possa ser mantido.

Essa proposição corrobora a contribuição de Mintzberg (1998) de não separar pensamento de ação.

\begin{abstract}
Embora seja verdade que muitas estratégias planejadas são mal concebidas, creio que 0 problema, freqüentemente, reside um passo além, na distinção que fazemos entre formulação e implementação - a premissa comum de que o pensamento deve ser independente (e preceder) à ação. (MINTZBERG, 1998, p.424)
\end{abstract}

Tal afirmação sustenta que o pensamento e ação acontecem em conjunto, e, mais do que isso, um deriva do outro. Na página seguinte, no entanto, o próprio autor se contradiz ao afirmar: "chamamos de estratégia emergente estratégias como esta da NFB, que surgem como se não houvesse." (MINTZBERG, 1998, p. 425)

$\mathrm{Na}$ verdade elas não surgem como se não houvesse, e sim, como variação de uma reta, ou seja, derivam da proposição original. Mintzberg (1998, p. 426) assume essa relação de dependência ao sugerir que nenhuma organização "tem conhecimento suficiente para prever antecipadamente tudo que venha a acontecer, para ignorar a aprendizagem ao longo do processo. $E$ ninguém pode ser suficientemente flexível a ponto de deixar as coisas acontecerem ao acaso, abrindo mão de todo 0 controle".

\title{
4 UMA NOVA METÁFORA
}

A metáfora da escultora foi de grande contribuição ao estudo da estratégia. No entanto, a metáfora que pode melhor explicar a formulação da estratégia é o Jazz. O Jazz é uma união de ritmo, fraseado, temas, arranjos, dinâmicas, tempo sincopado e swing (frase atribuída à cantora americana Diana Krall, uma das maiores expressões do Jazz Contemporâneo). 0 jazzista conhece a partitura da música que irá tocar. Muitas vezes ela já foi gravada e é de sua própria autoria. Entretanto, a própria natureza do jazz exige a improvisação. Assim, o jazzista nunca toca da mesma forma todas à vezes. A partir da partitura, ele se desdobra para cima e para baixo nas escalas de seu instrumento utilizando-se de muita inspiração para entregar à sua audiência um momento mágico. Ou seja, o jazzista parte de uma intenção musical, e à medida que evolui sobre o tema, cria novos desdobramentos que por sua vez criam uma nova sonoridade que deriva da proposta original. Os objetivos de satisfazer, surpreender e encantar a platéia são atingidos.

O jazz é considerado a música mais livre do planeta, tanto o músico quanto o ouvinte podem esquecer das regras e dos dogmas criados pelo mundo e se entregarem ao seu ritmo. A evolução do jazz pode fornecer um comparativo de como a improvisação associada à liberdade e ousadia fizeram com que o ritmo mudasse ao longo do tempo, sem deixar de ser jazz. Essa conotação de liberdade e inquietação surgiu junto com sua origem, no sul dos Estados Unidos, principalmente na cidade de Nova Orleans, no final do século XIX e início do século XX, quando o ritmo era considerado profano. Os negros americanos, discriminados e tratados como escravos foram os porta-vozes do jazz. Não importava se era cantado ou tocado, o que ele proporcionou aos negros americanos foi além do patriotismo ou da religião. Eles fizeram do jazz a sua identidade, que é respeitada e admirada até hoje em todo o mundo. No entanto, antes do estilo New Orleans, existia o chamado ragtime, cujo capital era Sedália, no Estado de Missouri. Em meados de 1910, um movimento de jazzistas "brancos" fora batizado de Dixieland. E foi em 1920, como conseqüência da intensa atividade musical que se desenvolveu o estilo denominado Chicago. Segundo Berendt (1975), grande parte do estilo Chicago 
está relacionada com a tentativa de imitação dos músicos de Nova Orleans feitas pelos músicos de Chigaco. Após o período "pianístico" do ragtime, o saxofone ganha importância especial e notoriedade.

Mas foi a partir do pianista Jelly Roll Morton e da cantora Bessie Smith que o jazz começou sua jornada. Seu primeiro grande expoente foi Louis Armstrong, na época trompetista de Joseph King Oliver. Armstrong se destacou não apenas como um instrumentista solo formidável, mas também como um cantor carismático e com um estilo muito próprio de interpretar. Já Duke Ellington é considerado o Mozart do jazz. Seus arranjos sofisticados e sua orquestra de virtuosos foram às novidades, no início dos anos 30 que regeram a era do swing. Junto a Ellington, outros músicos fizeram história: Benny Goodman, Artie Shaw, Woody Herman e Glenn Miller. Esta fase do jazz caracterizou-se pelo surgimento do "four beat jazz", no qual os quatro tempos do compasso levavam uma batida regular, diferentemente da predominância até então do formato "two beat jazz".

No meio dos anos 40, o jazz foi revolucionado pelo bebop. Esse estilo tem como característica principal a vocalização do instrumento. Os solos pareciam frases cantadas. Muitas vezes conseguiam ser desorientadas e magistrais ao mesmo tempo. Seus precursores foram o saxofonista Charlie Bird Parker, o trompetista Dizzy Gillespie e o pianista Thelonius Monk. Posteriormente surge o trompetista Miles Davis junto ao saxofonista John Coltrane e ambos criam o que ficou rotulado de cool jazz, considerado algo mais tranqüilo e requintado que o bebop. Segundo Berendt (1975), a grande característica do bebop era sua incrível flexibilidade e sua condução melódica extremamente nervosa. Para os críticos chegava-se ao "fim do jazz".

A década de 50 dá início ao "Cool, Hard Bop", que se originou de um solo que Miles Davis executara em 1947 num concerto ocorrido em Paris. Essa concepção musical dominou o jazz no início dos anos 50. Época que o ritmo se transferira para a Costa Oeste dos Estados Unidos, e é por isso que os especialistas costumam afirmar que Nova lorque é a verdadeira capital do jazz, pois foi lá que o ritmo se atualizou e assimilou diversas técnicas, embora sem se desligar das características básicas que 0 identificavam.

Em 1960 surge o Free Jazz, caracterizado pela entrada no campo livre da atonalidade, dissolução da simetria rítmica, incorporação de elementos musicais culturalmente variados, maior intensidade de execução instrumenta, e com o ruído passando a fazer parte da sonoridade.

Durante 0 início dos anos 70, Miles Davis volta à cena e começa uma união com o rock, criando o jazz fusion. Ele juntamente com o pianista Chick Corea e o guitarrista John Mclaughlin, à frente da Mahavishnu Orchestra, "subvertem" o jazz e conseguem atrair novos ouvintes. Apenas no início dos anos 80 é que uma nova influência é somada ao jazz, novamente tendo Miles Davis como precursor. Davis criou o que mais tarde foi chamado de acid jazz, uma mistura de jazz, rap e dance que até hoje é considerado um estilo que tem ajudado o jazz a se renovar e ficar mais acessível. Dentro dessa vertente destacam-se os grupos ingleses Incognito, Jamiroquai e Brand New Heavies e os americanos do Count Basic, James Taylor Quartet, Brooklyn Funk Essentials e US3.

E foi através da experimentação, da improvisação, das tentativas que o jazz partiu de um estilo musical e, ao agregar diversos elementos que acabaram por enriquecer a música, derivou em novos estilos sem que sua característica essencial fosse perdida, satisfazendo desta forma uma cada vez mais inquieta e exigente audiência. A formulação da estratégia se assemelha à performance dos músicos de jazz, pois parte de uma intenção cuja formalização gera um processo deliberado e que está sujeito às variações provocadas pela necessidade de adaptação ou mudança, que por sua vez geram modificações incrementais ou descontínuas (Miller \& Friesen, 1978), cujos desdobramentos levam ao alcance do objetivo primordial da organização, seja ele qual for.

Este comportamento de tentativa-e-erro e improvisação pode ser observado em determinadas empresas brasileiras. Exemplifica-se com o caso da Caloi, pois quando o mercado brasileiro foi aberto em 1994, ela era, até então, a líder do setor de bicicletas; começou então a diversificar suas atividades, incluindo a comercialização e distribuição de motores de popa, scooters e quadriciclos da marca Suzuki. Em 2000, a então gestão profissional da empresa liderada pela consultoria MGDK decidiu por 
enxugar os negócios que não eram ligados ao core business e incorporar outros que eram, como é o caso da linha fitness. Esta decisão de produto nasceu a partir da redefinição de negócio da empresa, com um conceito de vida saudável, que vai muito além de uma empresa produtora de bicicletas. De acordo com Tanure et al (2004, p.36), "para gerar os produtos voltados para o mercado de fitness, a Caloi deixou de realizar importações como anteriormente e fez uma parceria com a empresa Athletic Way [...] a empresa hoje coloca a sua marca, comercializa e fornece assistência técnica por meio de um canal de vendas constituído de lojas especializadas as chamadas bike shops". Ao ter clareza de sua definição de negócio a empresa derivou adequadamente sua estratégia planejada de forma a atender com escopo mais amplo os consumidores que buscam uma vida saudável.

Outro caso é o da empresa gaúcha RBS, um conglomerado de veículos multimídia, considerado um dos três maiores do País, e que começou através de uma empresa de rádio em 1957. De 1962 a 1996, durante 34 anos, a empresa buscou crescer sobre seu core business, através da compra, criação ou consolidação de novas unidades de negócio como emissoras de televisão, jornais e redes de rádios, expandindo para produção de conteúdo segmentado como a TVCOM e o Canal Rural. Entretanto, em 1992, a RBS lançou a NET Sul - pioneira em TV a cabo no mercado brasileiro - um ensaio na área de distribuição de conteúdo através da televisão por assinatura. Mas foi em 2000 que a maioria das variações sobre a reta foram conquistadas com o lançamento do projeto RBS Interativa, com a RBS Direct (Marketing Direto) e o portal de Internet clicRBS.

O projeto RBS Interativa estava baseado na criação dos segmentos de negócios Rural, Esportes e Jovem. O segmento de Esportes deveria cuidar da compra e venda de direitos esportivos de competições nos estados do Rio Grande do Sul e Santa Catarina. O segmento Jovem cuidaria das operações e conteúdo focados neste target e o segmento Rural de ser uma plataforma de relação com o agribusiness brasileiro. O projeto RBS Interativa foi modificado em meados de 2001 aproximadamente um ano após sua criação. RBS Direct e o portal de Internet foram adaptados e tiveram sua continuidade. Como o negócio de TV por assinatura não evoluíra no Brasil, buscou uma associação da Net Sul com a Globocabo, e tornou-se sócia da plataforma nacional de TV paga.

Tal qual a evolução do jazz deveria ser o comportamento estratégico das organizações. Um combinado de deliberação, tentativa (e erros) e improvisação à medida que o ambiente evolui, elementos são adicionados ao plano, gerando possíveis derivações estratégicas importantes, novos produtos e novos mercados.

\section{CONCLUSÃO}

Estratégia é um processo mais complexo do que parece. Não fosse assim, tantos autores e especialistas não concordariam e discordariam em sua origem, forma, deliberação ou emergência. $A$ conclusão a que se chega é a da verdadeira complexidade da estratégia. Tudo começa com uma intenção. A organização necessita ao mesmo tempo de um ponto de partida, ou seja, saber quem é e de uma intenção, uma visão, uma meta de longo prazo, um fim, sendo que deverão ser buscados os meios para atingi-lo. Na definição dos meios, surge o processo deliberado, ou seja, o estabelecimento de um "plano de ataque", um conjunto de desdobramentos táticos que são os meios provisionados para alcançar o objetivo.

Durante a consecução do plano, e estando em ambiente com acelerado nível de mudança um leque de oportunidades e ameaças surge a cada instante para desafiar a organização. Estas oportunidades e ameaças são absorvidas e a resposta apresenta-se através de movimentos de tentativa ou de improvisação. Partes do que se tinha como plano deliberado segue o rumo previsto, mas outras acabam tendo de fazer desvios de percurso através destas tentativas. As tentativas que funcionam são absorvidas. As que levam ao alcance do objetivo original passam a ser consideradas 
como nuances da estratégia original. Mas as que levam ao alcance de um novo produto, um novo mercado ou ao desdobramento através de um novo objetivo para um novo negócio tornam-se derivações.

Por este aspecto a relação com a evolução do jazz torna-se clara. A liberdade, a improvisação e a experimentação musical fizeram com que o ritmo fosse evoluindo e derivando em novas formas. Assim como no universo empresarial os desafios foram surgindo, assim como as oportunidades aproveitadas através de misturas sonoras, que geraram novos ritmos de jazz a partir do velho jazz.

Tal qual tocar jazz, tratar de estratégia é considerar um amplo leque de possibilidades para se chegar a um fim específico ou manter a flexibilidade de forma a se chegar a outros fins. Estas possibilidades surgem do desdobramento do plano estratégico proposto. Assim, apresenta-se o que se convenciona denominar de "estratégia derivada", pois é resultado de uma variação sobre a reta. Isso significa que estratégia não é algo acabado e sim um processo em constante desenvolvimento. Uma boa definição para o que é estratégia pode ser a resposta de Miles Davis, músico e compositor, sobre 0 que é jazz: "I'll play it first and tell you later" ("vou tocá-lo primeiro e responder o que é depois).

\section{REFERÊNCIAS}

ALLEN, R. O processo de criação da visão. HSM Management, n.9, p18-22, Jul-Ago, 1998

ANDERSON, M. The rise and fall of strategic planning. Sloan Management Review. V. 35, I. 2, p107108, Winter, 1994

ANSOFF, H. I. Corporate strategy. Harmondsworth: Penguin, 1965

AUSTIN, B. The rise and fall of strategic planning. The Academy of Management Executive. V. 8 I. 3 , p109-111 Aug. 1994

BERENDT, J. E. O Jazz: do rag ao rock. São Paulo: Perspectiva, 1975.

CAPON, Noel. The rise and fall of strategic planning. Academy of Management Review, V.21, I. 1 , p298-301, Jan. 1996

CHANDLER, A. D. Strategy and structure: chapters in the history of the american industrial enterprise. Cambridge, MA: MIT Press, 1962.

CHAKRAVARTHY, B. A New Strategy Framework for Coping with Turbulence. Sloan Management Review, vol. 38, n. 2, pp. 69-82, Winter 1997.

CHAKRAVARTHY, B. Flexible commitment: a key to strategic success. Strategy \& Leadership, May/Jun. 1996.

D'AVENI, R. Hypercompetition: managing the dynamics of strategic maneuvering. New York: Free Press, 1994.

DE GEUS, A. A empresa viva. São Paulo: Campus, 1998.

DIEGUEZ, C. Muito além do petróleo. Revista Exame. Disponível em: < www.exame.com.br>. Acesso em 12 dez. 2004. 
HAMMEL, G. Leading the revolution: how to thrive in turbulent times by making innovation a way of life. Boston, Massachusetts: Harvard Business School Press, 2002.

LEVITT, T. Marketing Myopia (HBR Classic). Harvard Business Review, July 1, 2004.

McCARTHY, D. View from the top: Henry Mintzberg on strategy and management. The Academy of Management Executive, V. 14 I. 3, p31-42, Aug. 2000

MARKIDES, C.; CUSUMANO, Michael A. Pensamento estratégico. São Paulo: Campus, 2002.

MILLER, D.; FRIESEN, P. H. Archetypes of strategy formulation. Management Science. V. 24 I. 9 , p921-933 May, 1978.

MINTZBERG, H. Safári de estratégia: um roteiro pela selva do planejamento estratégico. Porto Alegre: Bookman, 2001.

A criação artesanal da estratégia. In: MONTGOMERY, Cynthia A.; PORTER, Michael E. Estratégia: a busca da vantagem competitiva. Rio de Janeiro: Campus, 1998. 1994

Rethinking Strategic Planning: Parts I and II. Long Range Planning. V. 27, I. 3, p12-30, Jun,

The Rise and Fall of Strategic Planning. Harvard Business Review, V. 72, I. 1, p107-114, January-February, 1994. 1993.

.The Putfalls of Strategic Planning, California Management Review, V. 36, I. 1, p32-47, Fall,

Learning 1, Planning 0 (Reply to Igor Ansoff) Strategic Management Journal, V. 12, I. 6, p463466, Sep. 1991.

Crafting Strategy. Harvard Business Review. I. 3, p71-90, Summer, 1988.

Planning on the Left Side and Managening on the Right. Harvard Business Review. V. 54, I. 4 , p49-58, July August, 1976. 1967.

The Science of Strategy-Making, Industrial Management Review, V. 8, I. 2, p71-81, Spring

0 processo da estratégia. Porto Alegre: Bookman, 2001.

MINTZBERG, H.; HUY, Q. The Rhythm of Change. Sloan Management Review. V. 44, I. 4, p79-84, Summer, 2003

MINTZBERG, H.; LAMPEL, J. Reflecting on the Strategy Process. Sloan Management Review. V. 40, I. 3, p21-30, Spring 1999

MINTZBERG, H.; WATERS, J. Of Strategies, deliberate and emergent. Strategic Management Journal, V. 6, I. 3, p257-272, Jul-Sep, 1985 
MINTZBERG, H.; WESTLEY, F. Cycles of Organizational Change. Strategic Management Journal, Special Issue, V. 13, I. 8, p39-59, Winter 1992

MONTGOMERY, C. A.; PORTER, M. E. Estratégia: a busca da vantagem competitiva. Rio de Janeiro: Campus, 1998.

NADLER, D.; TUSHMANN, M. Types of organizational change: from increment improvment to discontinuous transformation. In: NADLER, $D$ et al. Discontinuous Change: leading organizational transformation. San Francisco: Jossey-Bass, 1995.

PADUAN, R. As cópias estão mais rápidas. Exame, p. 68/69, 27 jan. 2005.

PORTER, M. E. Estratégia competitiva: técnicas para análise de indústrias e da concorrência. 7a ed. Rio de Janeiro: Campus, 1991.

. What is strategy? Harvard Business Review. V. 74, I. 6, p61-78, Nov/Dec, 1996.

. From Competitive Advantage to Corporate Strategy. Harvard Business Review, V. 65, I. 3 , p43-59, May/Jun, 1987.

How Competitive Forces Shape Strategy. Harvard Business Review. V. 57, I. 2, p137-145, Mar/Apr, 1979.

PRAHALAD, C. K.; HAMEL, Gary. Competindo pelo futuro: estratégias inovadoras para obter o controle do setor e criar os mercados de amanhã. São Paulo: Campus, 1995.

Competing for the future. Harvard Business Review, V. 72, I. 4, p122-129, Jul/Aug, 1994.

The core competence of a corporation. Harvard Business Review, V. 68, I. 3, p79-91, May/Jun, 1990.

1993.

Strategy as stretch and leverage. Harvard Business Review, V. 71, I. 2, p75-84, Mar/Apr,

Strategic Intent. Harvard Business Review, V. 67, I. 3, p63-78, May/Jun, 1989.

SLOAN, A. P. My years with General Motors. Londres: Sedgewick \& Jackson, 1963

TANURE, Betânia; GOSHAL, Sumantra. Estratégia e gestão empresarial: construindo empresas brasileiras de sucesso. São Paulo: Campus, 2004.

TELLIS, G. J.; GOLDER, P. N. Singularidade e visão. In:__ Ação e visão: como vencer os que chegaram primeiro e como dominar mercados de forma duradoura. Rio de Janeiro: Campus, 2002.

TUSHMAN, M. L.;O’REILLY, C. A. Winning throught innovation: a pratical guide to leading organizational change and renewal. Boston: Harvard Business School Publishing, 1997

WALL, Stephen, Improvisação planejada. HSM Management, n. 47, V. 6, Nov-Dez, 2004

WHITTINGTON, Richard. 0 que é estratégia. São Paulo: Thompson, 2002. 


\section{STRATEGY AND JAZZ: A NEW PROCESS OF STRATEGIC FORMULATION}

What strategy really means and how strategies are created has been an emerging topic in the field of management. This article's main purpose is not to create a new division, but get together the theme, in order to consider strategy as a sequence of moments, that starts from strategic intent and planning, but allows the derivative behavior. The main conclusion is that the metaphoric comparison between strategy making and jazz, which some basic element of jazz performance, as experimentation and improvisation, join the collective notes, in order to bring magic moments to the audience. Improvisation and experimentation are related with jazz evolution, in which the significant and well-succeed derivative situations changed the music in a modern way, without loosing its temper. This occurs in companies as well, where tries and improvisations can bring strategic evolution.

Key Words: Strategy Making. Derivative Strategies. Jazz.

Data de Submissão: fevereiro de 2007 Data de Aceite: junho de 2007 